\title{
COMPORTAMENTO DE ZINCO E MANGANÊS DE PILHAS ALCALINAS EM UMA COLUNA DE SOLO
}

\author{
Demetrios Chiuratto Agourakis, Iara Maria Carneiro de Camargo, Marycel Barboza Cotrim e Marlene Flues* \\ Centro de Química e Meio Ambiente, Instituto de Pesquisas Energéticas e Nucleares, CP 11049, 05422-970 São Paulo - SP, Brasil
}

Recebido em 14/7/05; aceito em 27/1/06; publicado na web em 14/6/06

\begin{abstract}
BEHAVIOR OF ZINC AND MANGANESE FROM ALKALINE BATTERIES IN A SOIL COLUMN. The aim of this study was to evaluate the behavior of $\mathrm{Zn}$ and $\mathrm{Mn}$ in a soil column. Two soil columns were sampled, and four opened alkaline batteries were placed at the top of one soil column. An acid-rainwater solution $\left(\mathrm{HNO}_{3}\right.$ and $\mathrm{H}_{2} \mathrm{SO}_{4}$; $\left.\mathrm{pH} 4\right)$ was percolated through the battery contaminated column during one year. The results showed that the leaching of alkaline batteries caused enrichment of 70 and 11 times in the $\mathrm{Zn}$ and $\mathrm{Mn}$ concentration of the topsoil, respectively. Additionally, leaching of electrolyte (KOH) from the batteries increased the soil $\mathrm{pH}$ in the contaminated column.
\end{abstract}

Keywords: soil contamination; battery; metal.

\section{INTRODUÇÃO}

No Brasil são produzidas ao ano cerca de 3 bilhões de unidades entre pilhas e baterias para uso doméstico ${ }^{1}$. Tal quantidade gera preocupação, uma vez que é de conhecimento público que a maior parte do lixo doméstico é destinado a lugares inadequados para sua disposição.

Dentre as pilhas e baterias de uso doméstico, destacam-se as pilhas de zinco-carvão ou Leclanché (“Amarelinhas") e as alcalinas. Ambas são baterias primárias, ou seja, não são recarregáveis e têm como principais constituintes zinco e manganês. A principal diferença entre estes dois tipos de pilhas é a composição do eletrólito usado. Nas pilhas de zinco-carvão o material anódico (zinco) é encontrado na forma de um cilindro do metal em contato com o dióxido de manganês prensado, e o eletrólito utilizado é cloreto de amônio. Nas pilhas denominadas alcalinas, o zinco está presente na forma de pó aglutinado e o eletrólito utilizado é hidróxido de potássio, daí o nome pilha alcalina. A maior área superficial do zinco em pó e a maior condutividade do hidróxido de potássio em relação ao cloreto de amônio concedem à pilha maior durabilidade e desempenho. Segundo dados da ABINEE (Associação Brasileira da Indústria Eletro Eletrônica) de $1999^{1}$, a porcentagem de pilhas alcalinas vendidas no Brasil representa cerca de $30 \%$ do total das vendas no mercado. Em contrapartida, as pilhas alcalinas dominam o mercado nos EUA, por durarem cerca de seis vezes mais que as pilhas de zinco-carvão².

Durante o processo de descarga, a composição inicial muda em função das reações que ocorrem no ânodo e no cátodo. As reações parcial e global de descarga de uma pilha alcalina podem ser descritas pelas Equações 1, 2 e 3:

Pólo negativo (ânodo): $\mathrm{Zn}^{\circ}+2 \mathrm{OH}^{-} \longrightarrow \mathrm{Zn}(\mathrm{OH})_{2}+2 \mathrm{e}^{-}$

Pólo positivo (cátodo): $2 \mathrm{MnO}_{2}+\mathrm{H}_{2} \mathrm{O}+2 \mathrm{e}^{-} \longrightarrow \mathrm{Mn}_{2} \mathrm{O}_{3}+2 \mathrm{OH}^{-}(2)$

Total: $\mathrm{Zn}^{0}+2 \mathrm{MnO}_{2}+\mathrm{H}_{2} \mathrm{O} \longrightarrow \mathrm{Mn}_{2} \mathrm{O}_{3}+\mathrm{Zn}(\mathrm{OH})_{2}$

O produto da reação pode variar com a taxa de descarga.

A composição porcentual da pilha alcalina ${ }^{3,4}$ varia conforme o

*e-mail: mflues@ipen.br fabricante. O ânodo é composto de $12-25 \%$ de zinco metálico em pó em uma solução de 4-8\% de $\mathrm{KOH}$ (pH 13) e o cátodo, de 30$45 \%$ de dióxido de manganês e $2-6 \%$ de grafite compactados. O ânodo e cátodo são envoltos por capa de aço niquelada, separador de papel e isolante de nylon. Alguns componentes da pilha são orgânicos, como a capa de papelão e o grafite, e não causam danos ambientais. Por outro lado, componentes como aço, plásticos, Zn, $\mathrm{Mn}$ e outros metais $(\mathrm{Pb}, \mathrm{Cd}, \mathrm{Hg}, \mathrm{Ni}, \mathrm{Cu}$ e $\mathrm{Cr}$ ) presentes como impurezas no $\mathrm{MnO}_{2}$ ou aditivos para melhorar a eficiência da pilhas podem elevar a concentração de poluentes tóxicos nos aterros.

Valores de toxicidade dos componentes da pilha alcalina publicados em fichas de segurança ("MSDS-Material Safety Data Sheet") das empresas Eveready e Duracell ${ }^{4,5}$ apresentam somente valores de toxicidade como limite de exposição ocupacional para os componentes majoritários da pilha. Valores de toxicidade, levantados na OSHA ("Occupational Safety \& Health Administration") 6 mostram que a toxicidade de $\mathrm{Hg}, \mathrm{Cd}, \mathrm{Pb}, \mathrm{Ni}$ é bem maior que a de $\mathrm{Mn}$ e $\mathrm{Zn}$.

De acordo com MSDS da Duracell e Eveready ${ }^{4,5}$, a pilha é classificada como resíduo não perigoso. Os efeitos da exposição de pilha são pequenos enquanto os metais e outras substâncias químicas estiverem blindados dentro da embalagem da pilha. Uma exposição potencial pode ocorrer em caso de vazamento ou ruptura da blindagem da pilha. Considerações sobre impactos ambientais sugerem uma disposição adequada, pois as pilhas contêm $\mathrm{Hg}$ e podem prejudicar o meio ambiente.

Uma outra forma de apresentar a toxicidade de metais referente a solos contaminados é publicada por $\mathrm{McBride}^{7}$ (Tabela 1), com valores de concentração fitotóxica e níveis de toxicidade em ma-

Tabela 1. Toxicidade de metais

\begin{tabular}{lllll}
\hline Componente & \multicolumn{2}{c}{ Fitotoxicidade } & \multicolumn{2}{c}{ Toxicidade em mamíferos } \\
\hline $\mathrm{Cd}$ & $\mathrm{M} \mathrm{A}$ & $(5-30)$ & $\mathrm{A}$ & (acumulativo) \\
$\mathrm{Hg}$ & $\mathrm{A}$ & $(1-3)$ & $\mathrm{A}$ & (acumulativo) \\
$\mathrm{Mn}$ & $\mathrm{M} \mathrm{B}$ & $(300-500)$ & $\mathrm{M}$ & \\
$\mathrm{Ni}$ & $\mathrm{M} \mathrm{A}$ & $(10-100)$ & $\mathrm{M}$ & \\
$\mathrm{Pb}$ & $\mathrm{M}$ & $(30-300)$ & $\mathrm{A}$ & (acumulativo) \\
$\mathrm{Zn}$ & $\mathrm{M} \mathrm{B}$ & $(100-400)$ & $\mathrm{M} \mathrm{B}$ & \\
\hline
\end{tabular}

Nível de toxicidade: A (alta), M (média) e B (baixa). Valor entre parênteses representa a concentração tóxica para plantas $\left(\mu \mathrm{g} \mathrm{g}^{-1} \mathrm{de}\right.$ folha seca). Adaptada da ref. 7 
míferos. A Tabela 1 também mostra que $\mathrm{Hg}, \mathrm{Cd}, \mathrm{Pb}$ e Ni apresentam níveis tóxicos mais elevados que $\mathrm{Zn}$ e $\mathrm{Mn}$.

A composição do lixo urbano de São Paulo mostra que a porcentagem de resíduos perigosos é de $1 \%$, cabendo às pilhas nesse universo um valor de $9,2 \%{ }^{8}$. Apesar deste valor ser pequeno, torna-se significativo no que diz respeito à saúde pública e ao meio ambiente, devido as suas propriedades químicas (características de corrosividade, reatividade e toxicidade). Portanto, o descarte de pilhas no lixo urbano ou no solo gera problemas nas estações de tratamento de lixo, poluição das águas superficiais e subterrâneas e acumulação de substâncias tóxicas na cadeia alimentar (bioacumulação e biomagnificação) $)^{8,9}$. Tanto zinco quanto manganês, apesar de serem essenciais aos seres vivos em baixas concentrações, são particularmente tóxicos quando em concentrações elevadas.

Para minimizar e solucionar esta problemática ambiental, o governo definiu e aprovou uma política de gerenciamento de resíduos sólidos através da Resolução CONAMA 257/1999 ${ }^{10}$, estabelecendo procedimentos, responsabilidades e prazos de adequação quanto ao descarte e comercialização de produtos ou resíduos sólidos perigosos de uso industrial e domiciliar. Conforme o artigo 13 dessa resolução, as pilhas comuns, depois de exauridas, podem ser descartadas no lixo doméstico, desde que atendam aos limites previstos pelos artigos $5^{\circ}$ e $6^{\circ}$, quanto à quantidade dos metais $\mathrm{Hg}, \mathrm{Cd}$ e $\mathrm{Pb}$ em sua composição ( $\mathrm{Cd}: 0,015 \%$; $\mathrm{Pb}: 0,200 \%$ e $\mathrm{Hg}: 0,010 \%$ em peso na pilha). No entanto, os metais $\mathrm{Mn}$ e $\mathrm{Zn}$, que correspondem a aproximadamente $50 \%$ em massa da composição média da pilha alcalina $^{3,4}$, não são estabelecidos pela legislação.

Isso significa que a contaminação começa pela disposição inadequada, porém legalizada, das pilhas nos lixões, isto é, em aterros não controlados para onde é destinada a maior parte dos resíduos sólidos domiciliares do Brasil. O vazamento gradativo, principalmente dos metais tóxicos, irá atingir diretamente o compartimento solo. Os metais tendem com o tempo a migrar para os demais compartimentos do ecossistema, até atingirem diretamente o ser humano.

Em tese, todos os constituintes de uma pilha contribuem para a poluição do meio ambiente. Porém, sabe-se que são os metais tóxicos aqueles que representam maior risco ambiental, devido às capacidades de migração, bioacumulação e biomagnificação. Convém ressaltar também a habilidade que os metais tóxicos apresentam de se transportarem do solo para a raiz das plantas, o que representa a fração biodisponível do metal no solo, ou serem transportados por lixiviação para as águas subterrâneas.

A solubilidade dos metais tóxicos é estabelecida principalmente pelas propriedades físico-químicas do solo. Os parâmetros de maior influência são os valores de $\mathrm{pH}$, a presença de substâncias orgânicas e inorgânicas formadoras de complexos e, também, a concentração e espécie química do metal presente. Vários autores ${ }^{11,12}$ verificaram que entre as propriedades do solo o $\mathrm{pH}$ é o parâmetro que mais influencia a partição do metal entre o solo e a solução solo, ou seja, na adsorção e dessorção do metal. De modo geral, o pH neutro e ligeiramente alcalino favorece a adsorção do metal no solo, pois o metal está sujeito à precipitação com formação de ligações de difícil solubilização como hidróxidos, carbonatos e fosfatos, diminuindo sua disponibilidade para as plantas e lixiviação para as águas subterrâneas.

Os estudos de contaminação de solos visam o transporte do poluente e seu efeito potencial químico e biológico. A chave destes estudos está centrada na compreensão da forma de ligação do contaminante ao solo. Esses estudos são complexos, pois os solos variam muito em composição. Basicamente a fase sólida do solo consiste em uma fração inorgânica (óxidos, hidróxidos de $\mathrm{Fe}, \mathrm{Al}$ e Mn, carbonatos, sulfatos etc.), derivados da sua rocha original através do intemperismo e, também, de uma fase orgânica gerada na decomposição de plantas e animais ${ }^{7}$.
$\mathrm{Na}$ literatura encontram-se muitas pesquisas envolvendo a reciclagem de pilhas alcalinas no Brasil ${ }^{3,13-16}$, mas nenhuma delas estuda possíveis contaminações em solo. Dentro deste contexto, o objetivo deste trabalho foi estudar o comportamento de zinco e manganês de pilhas alcalinas em coluna de solo, proveniente da lixiviação destas por uma solução simuladora de chuva ácida no período de um ano.

\section{PARTE EXPERIMENTAL}

\section{Coleta das colunas de solo}

A coleta das amostras de coluna de solo foi realizada no bairro de Aparecidinha na cidade de Sorocaba, que está localizada na região sudoeste do Estado de São Paulo, a 96 km de distância da capital. O local da amostragem foi selecionado levando-se em consideração a ausência de atividade antrópica direta sobre o solo. Foram amostradas 2 colunas de solo $\left(\mathrm{h}=30 \mathrm{~cm}\right.$ e $\varnothing_{\text {int }}=11 \mathrm{~cm}$ ), sendo coletadas uma ao lado da outra, com distância de $5 \mathrm{~cm}$ entre elas (Figura 1).

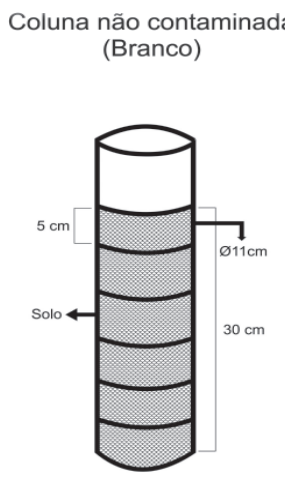

Coluna contaminada

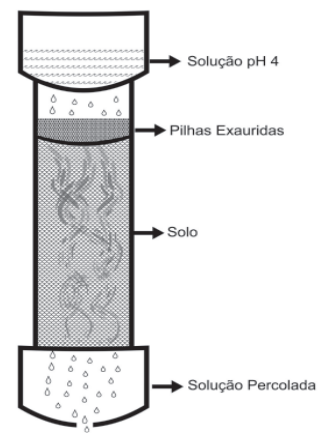

Figura 1. Esquema das colunas de solo branco (1) e contaminada pelas pilhas (2)

\section{Tratamento das colunas}

A coluna 1 (não contaminada) foi congelada e seccionada em seis frações de $5 \mathrm{~cm}$ e representa o branco ou solo referência da região. Cada fração foi colocada em bandeja para secagem ao ar. As frações da coluna 1 foram separadas para as análises de caracterização do perfil do solo. No topo da coluna 2 (contaminada) foram colocadas 4 pilhas tamanho AA da marca Duracell, todas exauridas, as quais foram seccionadas longitudinalmente e tiveram seus invólucros retirados, acelerando o processo de ruptura destas. A fim de evitar um contato direto das pilhas com o solo no topo da coluna, o que dificultaria os procedimentos analíticos posteriores, optou-se por colocar papel de filtro entre os dois.

Simulou-se uma solução de água de chuva com base nos estudos realizados por Fornaro ${ }^{17}$ e Galvão ${ }^{18}$ na região da grande São Paulo e na Cidade Universitária, respectivamente, para lixiviar as pilhas na coluna 2 de solo. Esta solução foi preparada na proporção 1:1 dos ácidos $\mathrm{HNO}_{3}$ e $\mathrm{H}_{2} \mathrm{SO}_{4}$ a pH 4, denominada como solução de chuva ácida. $\mathrm{O}$ volume de chuva ácida adicionado à coluna 2 correspondeu à média do índice pluviométrico mensal dos últimos 10 anos da cidade de São Paulo ${ }^{19}$. O volume adicionado à coluna foi calculado com base no índice em $\mathrm{mm}$ de chuva e o diâmetro do tubo; no período chuvoso foram adicionados entre 530 a $210 \mathrm{~mL}$ e no período de seca de 170 a $70 \mathrm{~mL}$, sendo a solução adicionada semanalmente à coluna 2 pelo período de 1 ano.

Após um ano de lixiviação das pilhas na coluna 2, esta foi congelada e seccionada conforme o procedimento para a coluna 1. As 
amostras de solo das colunas 1 e 2 foram secas e peneiradas em malha de $2 \mathrm{~mm}$ e quarteadas, a fim de se obter uma alíquota representativa de cada fração.

\section{Caracterização do solo}

Os ensaios de caracterização físico-química realizados nas amostras de solo da coluna 1 foram: granulometria (densímetro de Boyoucos) $)^{20}, \mathrm{pH}$ (em meio $\mathrm{KCl} 1 \mathrm{~mol} \mathrm{~L}^{-1}$ com proporção solo: solução 1:2,5) 21 $^{2}$ matéria orgânica (oxidação com $\mathrm{K}_{2} \mathrm{Cr}_{2} \mathrm{O}_{7}$ em meio $\mathrm{H}_{2} \mathrm{SO}_{4}$ e titulação com $\left.\mathrm{Fe}\left(\mathrm{NH}_{4}\right)_{2}\left(\mathrm{SO}_{4}\right)_{2}\right)^{21}$ e capacidade de troca catiônica (CTC) (saturação do solo com $\mathrm{BaCl}_{2}$, troca do Ba por $\mathrm{MgSO}_{4}$ e titulação com EDTA) ${ }^{22}$. Nas amostras de solo da coluna 2 foram realizadas somente análises de $\mathrm{pH}$. Todos os ensaios foram feitos em duplicata.

\section{Determinação da concentração de Zn e Mn do solo}

A concentração biodisponível dos metais nas amostras de solo das colunas 1 e 2, foi obtida a partir do método de extração única com EDTA-NH $\mathrm{N}_{4}$ A preparação das amostras de solo por extração com EDTA foi realizada em duplicata. A metodologia adotada baseia-se no método desenvolvido por $\mathrm{Ure}^{23}$. O processo consta em agitar $2 \mathrm{~g}$ de solo com $40 \mathrm{~mL}$ de EDTA-NH $40,05 \mathrm{~mol} \mathrm{~L}^{-1}(\mathrm{pH}=7,0)$ à temperatura ambiente durante $1 \mathrm{~h}, \mathrm{a}$ aproximadamente $10 \mathrm{rpm}$ em agitador vertical, centrifugar, filtrar, transferir as amostras para frascos de polietileno e acidificar para posterior determinação dos metais nas amostras de solo. A concentração biodisponível foi obtida por espectrometria de emissão atômica com fonte de plasma induzido, ICP-OES. O equipamento utilizado foi um ICP-OES - Spectro Flame M120 E da Spectro Analytical Instruments, com tocha axial.

A determinação da concentração total dos metais nas amostras de solo das colunas 1 e 2, por fluorescência de Raios-X, foi feita utilizando-se pastilhas de dupla camada preparadas usando $0,9 \mathrm{~g}$ de solo peneirado com malha 200 mesh, triturado com $0,1 \mathrm{~g}$ de $\mathrm{H}_{3} \mathrm{BO}_{3}$ e prensado sobre uma base de $\mathrm{H}_{3} \mathrm{BO}_{3}$. As leituras foram feitas utilizando-se um espectrômetro de fluorescência de raios-X (WDXRFS) RIX 3000 da Rigaku.

\section{RESULTADOS E DISCUSSÃO}

\section{Caracterização do solo}

Nas amostras do perfil de solo (6 frações) da coluna 1 (não contaminada) foram analisadas as características físico-químicas. O solo apresentou uma textura média com $20 \pm 1 \%$ de argila, $23 \pm 2 \%$ de silte, e $57 \pm 3 \%$ de areia. Aplicando estes dados ao triângulo americano adotado pela USDA ${ }^{20}$ ("United State Department of Agriculture Soil Staff') verificou-se que a textura classifica o solo como francoarenoso. A CTC que relaciona a capacidade de troca catiônica nos sítios de adsorção do solo apresentou uma média de $10 \pm 2 \mathrm{cmol} \mathrm{kg}$ ${ }^{1}$, caracterizando o solo com uma CTC média, segundo a classificação da $\mathrm{Agviselabs}^{24}$. $\mathrm{O} \mathrm{pH}$ e a porcentagem de matéria orgânica no solo mantiveram-se praticamente constantes, em torno de $4,1 \pm 0,1 \%$ (Figura 2) e 1,4 $\pm 0,1 \%$, respectivamente. De acordo com Brady ${ }^{25}, \mathrm{o}$ solo foi classificado como solo ácido e a baixa porcentagem de matéria orgânica caracterizou-o como solo mineral. Todas as características determinadas do solo da coluna 1 variam pouco no perfil da coluna e tendem a desfavorecer a adsorção de cátions neste solo, isto é, baixa porcentagem de matéria orgânica, além do $\mathrm{pH}$ ácido que favorece a lixiviação dos metais.

$\mathrm{O}$ pH da amostra de solo da coluna 2 (contaminada) também foi medido para avaliar a influência do $\mathrm{KOH}$ (eletrólito da pilha) no
pH do solo. Os resultados estão apresentados na Figura 2. A avaliação da Figura 2 aponta um aumento do $\mathrm{pH}$ no perfil do solo na coluna 2, na fração de $0-5 \mathrm{~cm}$, de $\mathrm{pH} 4$ para 6 nas colunas 1 e 2 , respectivamente. Nas frações subsequientes o aumento de $\mathrm{pH}$ foi menos acentuado, de $\mathrm{pH} 4$ para 5 nas colunas 1 e 2, respectivamente. $\mathrm{O}$ aumento de $\mathrm{pH}$ no perfil da coluna de solo 2 deve-se a lixiviação do eletrólito $\mathrm{KOH}$ presente na pilha pela solução de chuva ácida. Apesar desta solução de chuva ácida apresentar um caráter ácido ( $\mathrm{pH}=4)$, esta acidez não foi suficiente para a neutralização total do eletrólito $\mathrm{KOH}(\mathrm{pH}=13)$, permitindo uma alteração de $\mathrm{pH}$ do solo maior na camada superior e que se estendeu ao longo do perfil do solo com menor intensidade.

De acordo com Hellweg et al. ${ }^{26}$ o fator de retenção de vários metais depende do pH do solo e de sua tendência em formar hidrocomplexos, como mostra a Tabela 2. Uma avaliação do comportamento do $\mathrm{Zn}$ com base nos dados da Tabela 2 mostra que o fator de retenção deste a $\mathrm{pH} 4$ é 2 e quando $\mathrm{pH}$ do solo aumenta para 6, este fator de retenção se eleva para 4,5, favorecendo um aumento da adsorção do $\mathrm{Zn}$ pelo solo.

Tabela 2. Fator de retenção dos metais no solo em função do pH

\begin{tabular}{lllllll}
\hline Valores de $\mathrm{pH}$ & 4,0 & 4,5 & 5,0 & 5,5 & 6,0 & 6,5 \\
\hline $\mathrm{Cd}^{2+}$ & 1,5 & 2 & 3 & 3,5 & 4 & 4,5 \\
$\mathrm{Zn}^{2+}, \mathrm{Ni}^{2+}$ & 2 & 3 & 3,5 & 4 & 4,5 & 5 \\
$\mathrm{Cu}^{2+}, \mathrm{Cr}^{3+}$ & 3 & 4 & 4,5 & 5 & 5,5 & 6 \\
$\mathrm{~Pb}^{2+}, \mathrm{Hg}^{2+}$ & 4 & 5 & 6 & 7 & 8 & 9 \\
\hline
\end{tabular}

Adaptada da ref. 26

Para avaliar o comportamento dos metais $\mathrm{Zn}$ e Mn nas colunas de solo em estudo frente às variações de $\mathrm{pH}$ apresentadas na Figura 2, determinou-se as concentrações total e biodisponível destes metais. Com esses dados foram traçados os gráficos do perfil do solo em função da concentração do elemento na coluna 1 (não contaminada) e coluna 2 (contaminada). Os gráficos são apresentados nas Figuras 3 e 4 para $\mathrm{Zn}$ e $\mathrm{Mn}$, respectivamente.

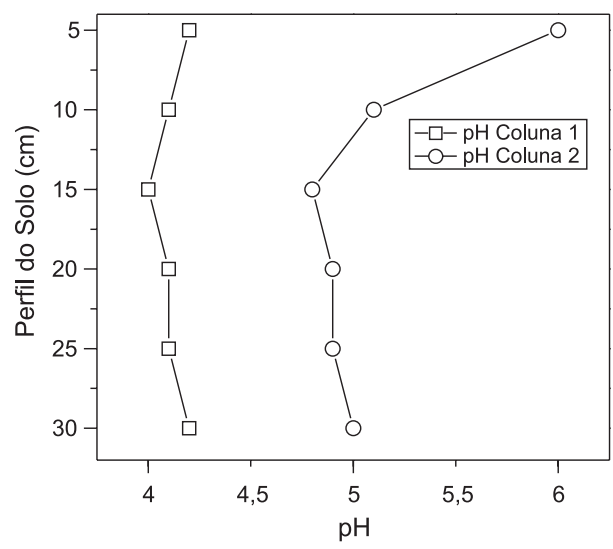

Figura 2. Variação do pH nas colunas de solo branco (1) e contaminada pelas pilhas (2)

Nas amostras de solo da coluna não contaminada (coluna 1) as concentrações total e biodisponível encontradas, variaram entre 11 e 18 e 0,47 a $2,53 \mathrm{mg} \mathrm{kg}^{-1}$ para o $\mathrm{Zn}$ e entre 101 e 121 e entre 1,70 e 4,12 $\mathrm{mg} \mathrm{kg}^{-1}$ para o $\mathrm{Mn}$, respectivamente.

Na coluna 2, que foi contaminada com as pilhas, foram obtidos valores de concentrações total e biodisponível que variaram entre 
15 e 1256 e entre 0,46 e $414,6 \mathrm{mg} \mathrm{kg}^{-1}$ para o $\mathrm{Zn}$ e entre 194 e 1146 e entre 6,76 e $153,4 \mathrm{mg} \mathrm{kg}^{-1}$ para o $\mathrm{Mn}$, respectivamente, apresentando valores de concentração bem mais elevados na camada superior da coluna de solo (Figura 3 e 4).

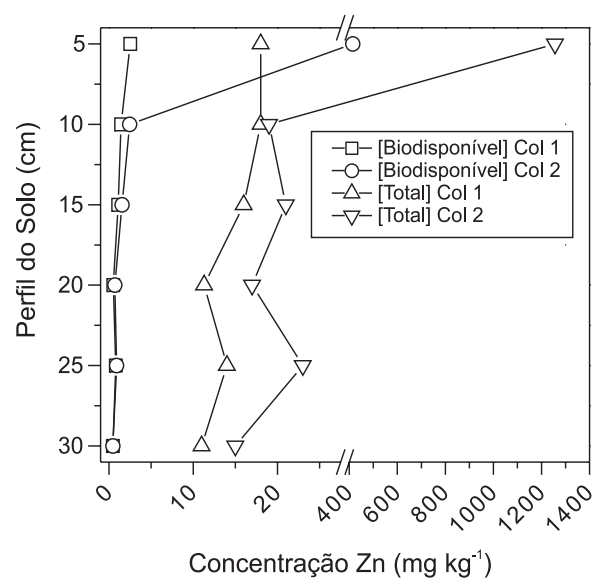

Figura 3. Concentração total (T) e biodisponível (B) em $\mathrm{mg} \mathrm{kg}^{-1}$ de $\mathrm{Zn}$ ao longo do perfil de solo $(0-30 \mathrm{~cm})$ das colunas branco (1) e contaminada pelas pilhas (2)

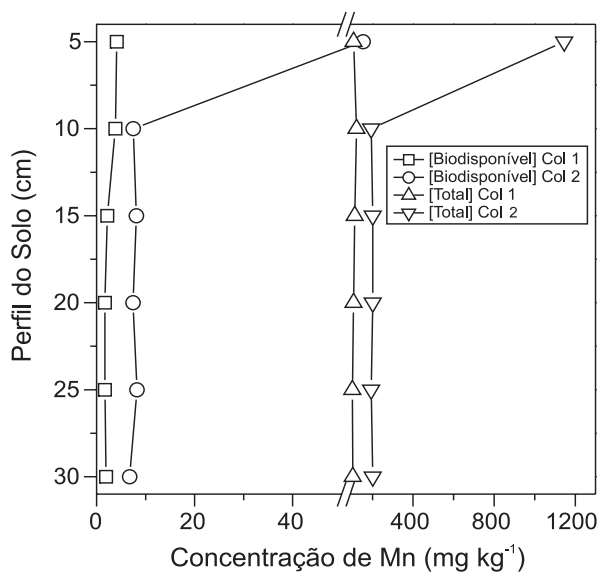

Figura 4. Concentração total (T) e biodisponível (B) em $\mathrm{mg} \mathrm{kg}^{-1}$ de Mn ao longo do perfil de solo $(0-30 \mathrm{~cm})$ das colunas branco (1) e contaminada pelas pilhas (2)

Para avaliar a contaminação do solo comparou-se a concentração total do Zn, $1256 \mathrm{mg} \mathrm{kg}^{-1}$, obtido na camada superior da coluna contaminada com os valores de intervenção (valor acima do qual existe risco potencial à saúde humana) de $\mathrm{Zn}\left(500 \mathrm{mg} \mathrm{L}^{-1}\right)$, para solo de proteção máxima, estabelecida pela Companhia de Tecnologia de Saneamento Ambiental do Estado de São Paulo (CETESB) ${ }^{27}$. Observou-se que a concentração de Zn ultrapassa o valor estabelecido pela CETESB. No caso do Mn não foi possível esta comparação já que a CETESB não estabeleceu valores de intervenção para Mn.

\section{Interação pilha-solo}

Como descrito anteriormente na introdução, a provável reação que ocorre durante o processo de descarga de uma pilha alcalina é representado pela Equação 3. De acordo com Bartolozzi ${ }^{16}$, a pilha depois de exaurida pode ainda conter $30 \%$ de $\mathrm{Zn}^{\circ}$ na sua composição, mos- trando que não ocorre uma reação de oxi-redução total. Analisando a reação da Equação 3 pode-se supor que a pilha exaurida apresenta na sua composição zinco e manganês nas duas formas, oxidada e reduzida, além do eletrólito $\mathrm{KOH}$. A pilha exaurida aberta foi lixiviada com a solução de chuva ácida, $\left(\mathrm{H}_{2} \mathrm{SO}_{4}+\mathrm{HNO}_{3} \mathrm{pH}=4\right)$, e as seguintes reações ${ }^{3}$ (Equações 4 a 10) poderiam ocorrer

$$
\begin{aligned}
& \mathrm{ZnO}+2 \mathrm{H}^{+} \longrightarrow \mathrm{Zn}^{2+}+\mathrm{H}_{2} \mathrm{O} \\
& \mathrm{Zn}^{0}+2 \mathrm{H}^{+} \longrightarrow \mathrm{Zn}^{2+}+\mathrm{H}_{2} \\
& \mathrm{KOH}+\mathrm{H}^{+} \longrightarrow \mathrm{K}^{+}+\mathrm{H}_{2} \mathrm{O} \\
& 2 \mathrm{KOH}+1,5 \mathrm{O}_{2} \longrightarrow 2 \mathrm{KO}_{2}+\mathrm{H}_{2} \mathrm{O} \\
& \mathrm{Mn}_{2} \mathrm{O}_{3}+2 \mathrm{H}^{+} \longrightarrow \mathrm{Mn}^{2+}+\mathrm{MnO}_{2}+\mathrm{H}_{2} \mathrm{O} \\
& 2 \mathrm{KO}_{2}+2 \mathrm{H}^{+} \longrightarrow 2 \mathrm{~K}^{+}+\mathrm{H}_{2} \mathrm{O}_{2}+\mathrm{H}_{2} \mathrm{O} \\
& \mathrm{MnO}_{2}+2 \mathrm{H}^{+}+\mathrm{H}_{2} \mathrm{O}_{2} \longrightarrow \mathrm{Mn}^{2+}+2 \mathrm{H}_{2} \mathrm{O}+\mathrm{O}_{2}
\end{aligned}
$$

As reações acima apresentadas mostram que zinco e manganês inicialmente presentes na pilha tendem preferencialmente a formar cátions bivalentes. A solução resultante da lixiviação das pilhas infiltrou na coluna de solo. Esta solução contém $\mathrm{KOH}$ não neutralizado, $\mathrm{Zn}$ e $\mathrm{Mn}$ nas seguintes formas químicas: $\mathrm{Zn}^{0}$ coloidal e $\mathrm{MnO}_{2}$ coloidal, $\mathrm{Zn}^{2+}$ e $\mathrm{Mn}^{2+}$.

De acordo com Mc Bride 7 , os metais contaminantes quando introduzidos no meio ambiente podem formar complexos na esfera interna ou externa dos componentes do solo, com diferentes ligantes inorgânicos $\left(\mathrm{OH}^{-}, \mathrm{HCO}_{3}^{-}\right)$ou orgânicos (ácidos húmicos e fúlvicos). A força e o caráter da ligação entre os metais e o solo determinam a concentração dos mesmos na fase líquida do solo (solução do solo). Conforme o tipo de interação ou especiação ocorrida, o metal estará mais móvel e disponível para os demais compartimentos da biosfera.

\section{Influência do pH na retenção de $\mathrm{Zn}$ e Mn}

Conforme discutido na introdução, o pH é considerado um parâmetro importante do solo que influenciam a mobilidade dos metais.

Com os valores das concentrações total e biodisponível de Zn e Mn apresentados nas Figuras 3 e 4, calculou-se a razão de retenção dos metais entre as colunas 1 e 2 nas várias frações do solo. Os resultados estão apresentados na Tabela 3 .

Tabela 3. Razão de retenção de Zn e Mn entre as colunas de solo 1 e 2

\begin{tabular}{lcccc}
\hline $\begin{array}{l}\text { Fração } \\
(\mathrm{cm})\end{array}$ & $\begin{array}{c}\text { Zn } \\
\text { Total }\end{array}$ & $\begin{array}{c}\text { Zn } \\
\text { Biodisponível }\end{array}$ & $\begin{array}{c}\text { Mn } \\
\text { Total }\end{array}$ & $\begin{array}{c}\text { Mn } \\
\text { Biodisponível }\end{array}$ \\
\hline $0-5$ & 70 & 160 & 11 & 40 \\
$5-10$ & 1,1 & 1,7 & 1,8 & 2,0 \\
$10-15$ & 1,3 & 1,4 & 1,6 & 3,7 \\
$15-20$ & 1,5 & 1,3 & 1,8 & 4,4 \\
$20-25$ & 1,6 & 1,1 & 1,9 & 4,8 \\
$25-30$ & 1,4 & 1,0 & 1,9 & 3,5 \\
\hline
\end{tabular}

Observando as Figuras 3 e 4 e as razões de retenção apresentadas na Tabela 3, nota-se um acúmulo de $\mathrm{Zn}$ e Mn na fração de $0-5 \mathrm{~cm}$ tanto para a concentração total quanto para a biodisponível. A retenção de $\mathrm{Zn}$ foi mais pronunciada (razão 70 para concentração total e 160 para a biodisponível) que a de Mn (razão 11 total e 40 
biodisponível), como mostram os valores da Tabela 3. Nas demais frações também foram observados acúmulos de $\mathrm{Zn}$ e Mn na coluna contaminada, tanto para a concentração total quanto para a biodisponível, porém bem menor se comparada à fração superficial.

É importante salientar que a presença do eletrólito forte $(\mathrm{KOH})$ em quantidades significativas (4-8\% em massa da pilha $)^{4}$ nas pilhas alcalinas foi responsável pela elevação do $\mathrm{pH}$ ocorrida na coluna 2 e se deve a íons $\mathrm{OH}^{-}$livres, que não foram neutralizados pela solução de chuva ácida com a qual a coluna foi lixiviada, como mostra a Figura 2. A aplicação da matriz de correlação de Pearson mostrou a existência de uma alta correlação entre as concentrações de $\mathrm{Zn}, \mathrm{Mn}$ versus o $\mathrm{pH}$ do solo da coluna $2(\mathrm{r}=0,97)$, indicando que a retenção destes metais no solo foi fortemente influenciada pelo pH do solo, o que não ocorreu na coluna 1 onde a correlação entre $\mathrm{Zn}, \mathrm{Mn}$ versus o $\mathrm{pH}$ foi menor $(\mathrm{r}=0,54)$.

A análise dos valores de concentrações total e biodisponível de Zn e Mn nas diversas frações das colunas 1 e 2 indicou o pH como um fator bastante importante a ser considerado na retenção de Zn e Mn no solo, fato concordante com a literatura. De acordo com Podlesáková et al. ${ }^{28}, \mathrm{Zn}$ e Mn apresentaram mobilidades negativamente correlacionadas com o $\mathrm{pH}$, sendo este o fator preponderante. Para estes metais foi possível, por meio de análises de regressão múltipla, deduzir equações que possam predizer a mobilidade dos mesmos no solo.

Segundo Falkengren-Grerup e Tyler ${ }^{29}$, o Mn apresentou correlação negativa com o pH, sendo este mais móvel a valores de $\mathrm{pH}$ em torno de 5,5. Acima deste valor, o Mn foi encontrado sob formas insolúveis e não trocáveis.

Tyler $^{30}$ afirmou que o comportamento do $\mathrm{Zn}$ em relação ao $\mathrm{pH}$ pode ser explicado pela adsorção dos íons $\mathrm{Zn}^{2+}$ nos óxidos e aluminossilicatos do solo, provocando a imobilização deste em valores de $\mathrm{pH}$ acima de 5.

A avaliação da lixiviação de pilhas alcalinas em uma coluna de solo, pelo período de um ano, indicou uma alteração nos valores de $\mathrm{pH}$ do solo provocada pelo eletrólito $(\mathrm{KOH})$ lixiviado da pilha. Essa variação de $\mathrm{pH}$ influenciou a retenção de $\mathrm{Zn}$ e $\mathrm{Mn}$, principalmente na fração superior da coluna de solo. Observou-se, também, que o pH favoreceu mais a retenção de Zn que de Mn (Tabela 3). Este comportamento foi confirmado por Blume ${ }^{31}$, que mostrou ser a retenção de $\mathrm{Zn}$ em solos favorecida por valores de $\mathrm{pH}$ a partir de 5,5, o mesmo ocorrendo com o manganês, somente em $\mathrm{pH}$ superior a 6 .

\section{CONCLUSÃO}

Neste trabalho avaliou-se o comportamento de $\mathrm{Zn}$ e Mn provenientes de pilhas alcalinas em uma coluna de solo, pelo período de um ano. Os resultados mostraram um aumento nas concentrações de $\mathrm{Zn}$ e Mn, na coluna de solo contaminada, principalmente na camada superficial.

Concluiu-se que o $\mathrm{pH}$ foi uma característica do solo bastante importante na retenção de $\mathrm{Zn}$ e Mn na camada superficial. A elevação do $\mathrm{pH}$ do solo foi causada pelo eletrólito da pilha que não foi totalmente neutralizado. Essa elevação, entretanto, não foi suficiente para imobilizar completamente o Mn na camada superficial, permitindo também seu acúmulo ao longo do perfil da coluna de solo.

Portanto, o descarte indiscriminado de pilhas alcalinas no solo, poderá acarretar em um incremento no $\mathrm{pH}$ e na concentração de me- tais, como Zn e Mn, inicialmente nas camadas superiores do solo e, a longo prazo, provavelmente também nas camadas subseqüentes. Apesar da baixa e moderada toxicidades do $\mathrm{Zn}$ e $\mathrm{Mn}^{7}$ e destes dois metais não serem controlados pela Resolução CONAMA 257/1999 ${ }^{10}$, observou-se no presente trabalho que o descarte de pilhas alcalinas no solo tende a aumentar a concentração de $\mathrm{Zn}$ e $\mathrm{Mn}$, podendo ultrapassar os valores de intervenção para solo estabelecidos pela CETESB $^{27}$.

\section{REFERÊNCIAS}

1. http://abinee.org.br, acessada em Novembro 1999.

2. Hurd, D. J.; Muchnick, D. M.; Schedler, M. F.; Mele, T.; Recycling of consumer dry cell batteries, $1^{\text {st }}$ ed., Noyes Data Corporation: New Jersey, 1993.

3. Souza, C. C. B. M.; Oliveira, D. C.; Tenório, J. A. S.; J. Power Sources 2001, 103, 120.

4. www.delta-education.com/msds/alkaline_battery.pdf, acessada em Novembro 2005.

5. www.duracell.com/oem/safety/pdf/2002_8E.pdf, acessada em Novembro 2005

6. www.OSHA.gov, acessada em Novembro 2005.

7. McBride, M. B.; Environmental Chemistry of Soils, Oxford Univ. Press: New York, 1994.

8. BSLU-(Bayerisches Staatsministerium für Landesentwicklung und Umweltfragen); Problemabfälle aus Haushalten in Ausgewählten Gebietskörperschaften Bayerns, München, September 1994.

9. USEPA (Environmental Protection Agency); A Handbook for Small Businesses, EPA530-K-95-001, 1996.

10. CONAMA (CONSELHO NACIONAL DO MEIO AMBIENTE); Resolução No.257, 30 Junho, 1999, Diário Oficial da União, 22 Julho, 1999.

11. Buchter, B.; Davidoff, J.; Amacher, M. C.; Hinz, C.; Iskandar, I. K.; Selim, H. M.; Soil Sci. 1989, 148, 370.

12. Soares, M. R.; Tese de Doutorado, Universidade de São Paulo, Brasil, 2004

13. Freitas, M. B. J. G.; Pietre, M. K.; J. Power Sources 2005, 143, 270.

14. Salgado, A. L.; Veloso, A. M. O.; Pereira, D. D.; Gontijo, G. S.; Salum, A.; Mansur, M. B.; J. Power Sources 2003, 115, 367.

15. Freitas, M. B. J. G.; Pietre, M. K.; J. Power Sources 2004, 128, 343.

16. Vatistas, N.; Bartolozzi, M.; Arras, S., J. Power Sources 2001, 101, 182.

17. Fornaro, A.; Dissertação de Mestrado, Universidade São Paulo, Brasil, 1991.

18. Galvão, P.; Dissertação de Mestrado, Universidade São Paulo, Brasil, 1996.

19. http://www.sigrh.sp.gov.br, acessada em Agosto 2001.

20. USDA-United State Department of Agriculture Soil Staff; Soil Taxonomy, Washington, 1974.

21. Empresa Brasileira de Agropecuária; Manual de métodos de análise de solo, Centro Nacional de Pesquisas de Solos, 2a . ed., Rio de Janeiro, 1997.

22. Rhoades, J. D.. Em., Methods of soil analysis; Page, A. L., ed., Madison, A.S.A., $2^{\text {nd }}$ ed., 1982, part 2, p. 149.

23. Ure, A. M.; Quevauviller, P. H.; Muntau, H.; Griepink, B.; Int. J. Environ. Anal. Chem. 1993, 51, 135.

24. http://www.agviselabs.com, acessada em Agosto 2005

25. Brady, N. C.; Buckman, H. O.; Natureza e propriedades do solo. $7^{\mathrm{a}} \mathrm{ed}$., Livraria Freitas Bastos S.A.: São Paulo,1989.

26. Hellweg, S.; Fischer, U.; Hofstetter, T. B.; Hungerbühler, K.; J. Cleaner Production 2005, 13, 341 .

27. Companhia de Tecnologia de Saneamento Ambiental; Relatório de estabelecimento de valores orientadores para solos e águas subterrâneas no Estado de São Paulo. CETESB, São Paulo: 2001.

28. Podlesáková, L. E. Em Trace Elements in Soil; Iskandar, L. K., ed.; CRC Press: London, 2001.

29. Falkengren-Grerup, U.; Tyler, G.; Z. Pflanzenernährung und Bodenkunde 1993, 156, 365.

30. Tyler, G.; Nordic J. Botany 1996, 16, 609.

31. Blume, H-P., Handbuch des Bodenschutzes, Ecomed: Landsberg, Germany, 1992, Vol. 2. 